УДК 37

DOI $10.21661 / \mathrm{r}-552407$

\title{
T.H. Тиосова
}

\section{ФОРМИРОВАНИЕ ЗАИНТЕРЕСОВАННОСТИ У СТУДЕНТОВ В ЗДОРОВОМ ОБРАЗЕ ЖИЗНИ}

Аннотация: данная статья посвящена анализу результатов опроса, проведенного среди студентов экономического факультета Владивостокского филиала Российской таможенной академии. Главной темой опроса является тема заинтересованности студентов в формировании здорового образа жизни. Во время данного исследования использовался метод анализа результатов анкетирования среди студентов экономического факультета Владивостокского филиала Российской таможенной академии и анализ научной литератуpbl, обозревающий данный вопрос.

Ключевые слова: здоровый образ жизни, студенты, второй курс, анкетирование, физическая культура.

\section{T.N. Tiosova}

\section{DEVELOPMENT OF INTEREST IN HEALTHY LIFESTYLE} AMONG STUDENTS

Abstract: this article analyzes the results of a survey conducted among students of the faculty of Economics of the Vladivostok branch of the Russian Customs Academy. The main topic of the survey is the interest of students in the formation of a healthy lifestyle. During this research the method of the analysis of results of questioning among students and the analysis of the scientific literature reviewing this question was used.

Keywords: healthy lifestyle, students, second year, questioning, physical culture.

Актуальность исследований ЗОЖ среди молодежи вызвана критическим состоянием физического и духовного развития поколения. Причина кроется в распространении моделей поведения, характеризующихся высокой долей пове- 
денческих факторов риска (курение, алкоголь, употребление токсических и психотропных веществ, клубная культура и др.) [1, с. 32]. Поэтому состояние здоровья современных российских студентов вызывает большую тревогу.

Целью данной работы является изучение заинтересованности в здоровом образе жизни среди студентов первого, второго и третьего курсов экономического факультета Владивостокского филиала Российской таможенной академии. А также оценить состояние здоровья студентов и их желание в плане его улучшения.

Студентам было предложено ответить на вопросы анкеты, заранее разработанной нами. Анкета состояла из 15 вопросов, которые наиболее полно информируют нас об уровне формирования и популяризации ЗОЖ среди студентов. Среди данных вопросов нами отобрано несколько наиболее точно описывающих рассматриваемую проблему.

В нашем анкетировании приняли участие студенты трех курсов экономического факультета Владивостокского филиала Российской таможенной академии (группа первого курса - 30 человек, второго курса - 23 человека, третьего курса - 21 человек). Таким образом, в опросе приняло участие 74 человека. Результаты, полученные в ходе анкетирования, были проанализированы и наглядно представлены в виде диаграмм. Приведем только некоторые из них. Например, чтобы понять, как студенты характеризуют свой уровень здоровья, были заданы следующие вопросы: «Как вы оцениваете состояние своего здоровья?» (рис. 1).

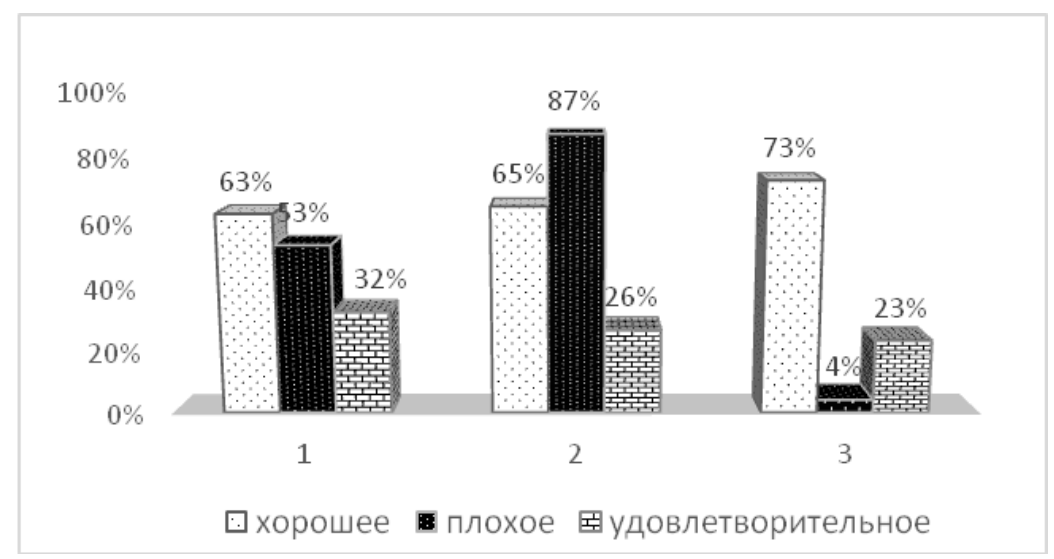

Рис. 1. Оцените состояние своего здоровья (\%) 
В соответствии с полученными данными, у студентов младших курсов по сравнению со старшекурсниками выявлен более высокий уровень заболеваемости. Можно утверждать, что ещё до поступления в учреждения профессионального образования здоровье молодых людей ослаблено под воздействием различных неблагоприятных факторов. В дальнейшем процесс адаптации к обучению в вузе оказывает влияние на показатели физического, психического и социального здоровья. Поэтому возникает повод говорить о необходимости создания условий для формирования здорового образа жизни студентов в процессе обучения.

Чтобы понять, какие факторы в наибольшей степени ослабляют здоровье студентов, обратимся к таким вопросам как: «Как часто употребляете алкоголь?» (рис. 2), и «Ваше отношение к курению?» (рис. 3).

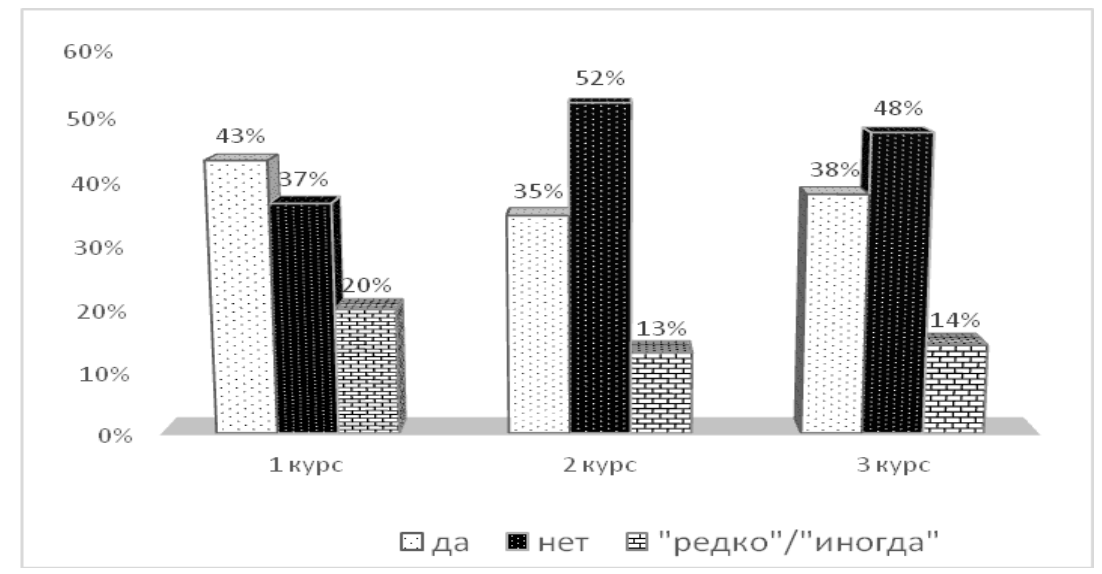

Рис. 2. Вы употребляете алкоголь (\%)

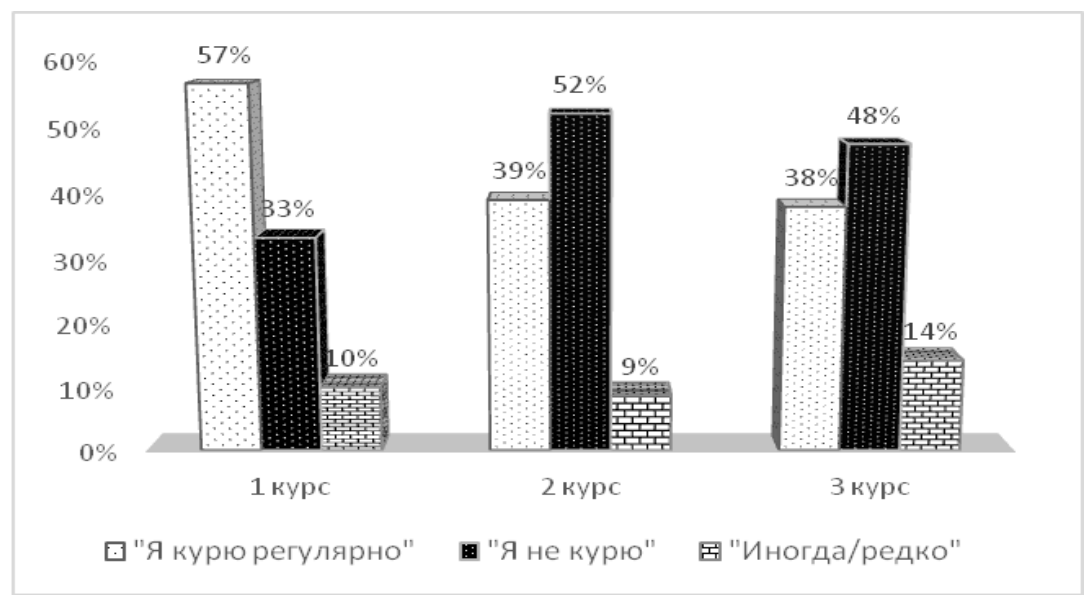

Рис. 3. Ваше отношение к курению (\%)

Таким образом, здоровье студентов всех трех курсов подвергается рискам со стороны курения и алкоголя. 
Всё же стоит обратить внимание на отношение самих студентов к вредным привычкам, а также оценить их заинтересованность в борьбе с ними. Так, на вопрос: «Вы готовы отказаться от вредных привычек?» (Рис.4) 70\% первокурсников, $74 \%$ второкурсников и $81 \%$ студентов третьего курса готовы отказаться от своих вредных привычек.

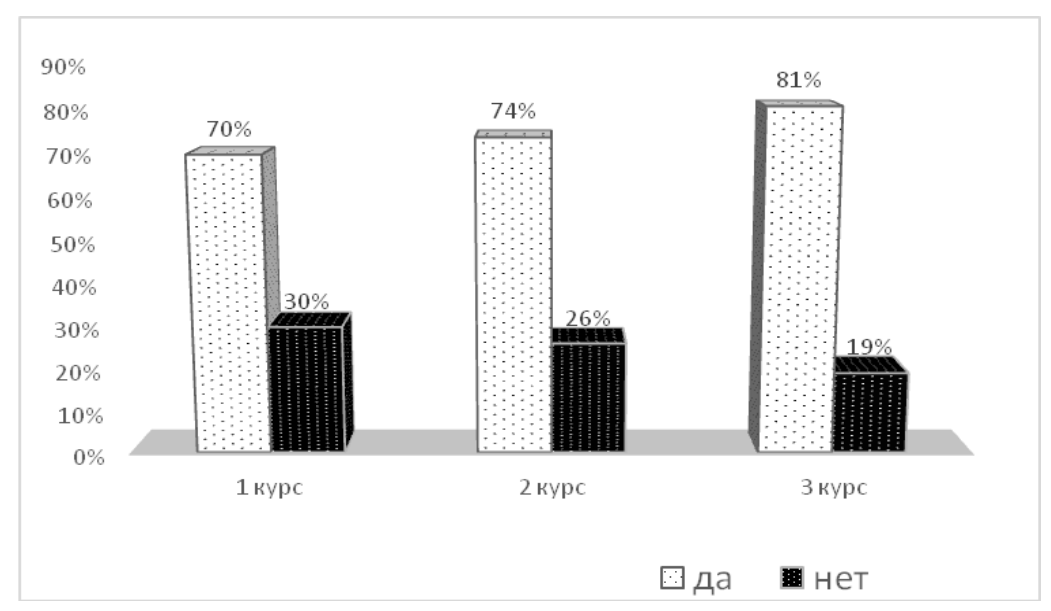

Рис. 4. Готовность отказаться от вредных привычек (\%)

Для изучения общего отношения студентов к культуре здорового образа жизни, были предусмотрены вопросы: «Необходимо ли придерживаться принципов здорового образа жизни?» (рис. 5), «Какие условия для сохранения здоровья наиболее важны?» (рис. 6).

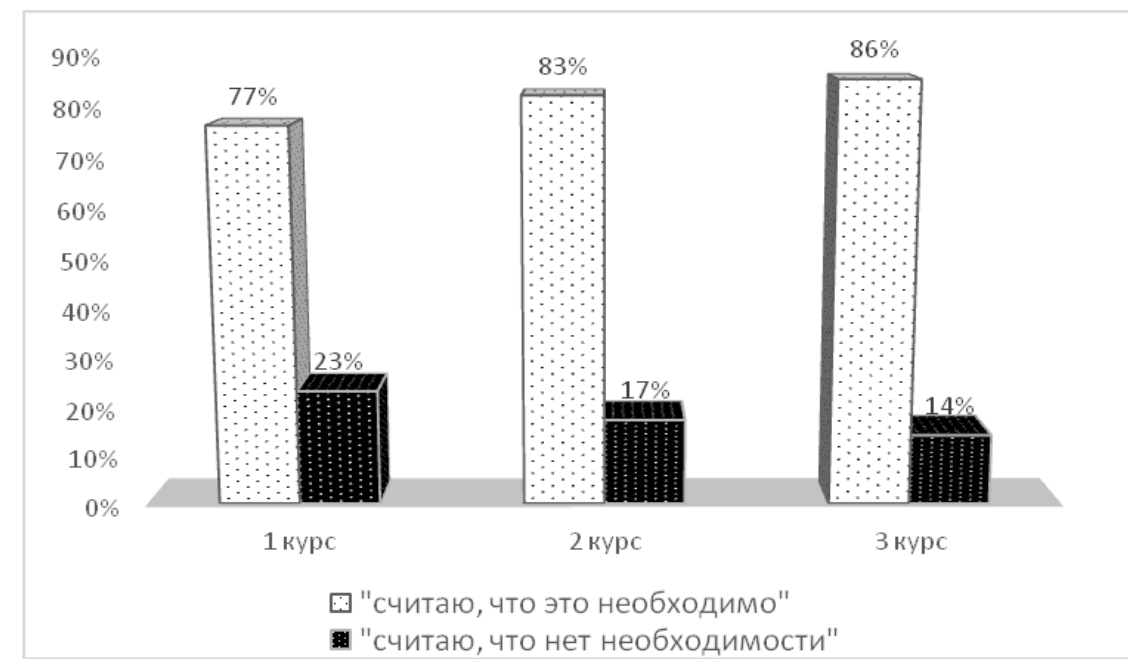

Рис. 7. Необходимость придерживаться принципов здорового образа жизни (\%) 


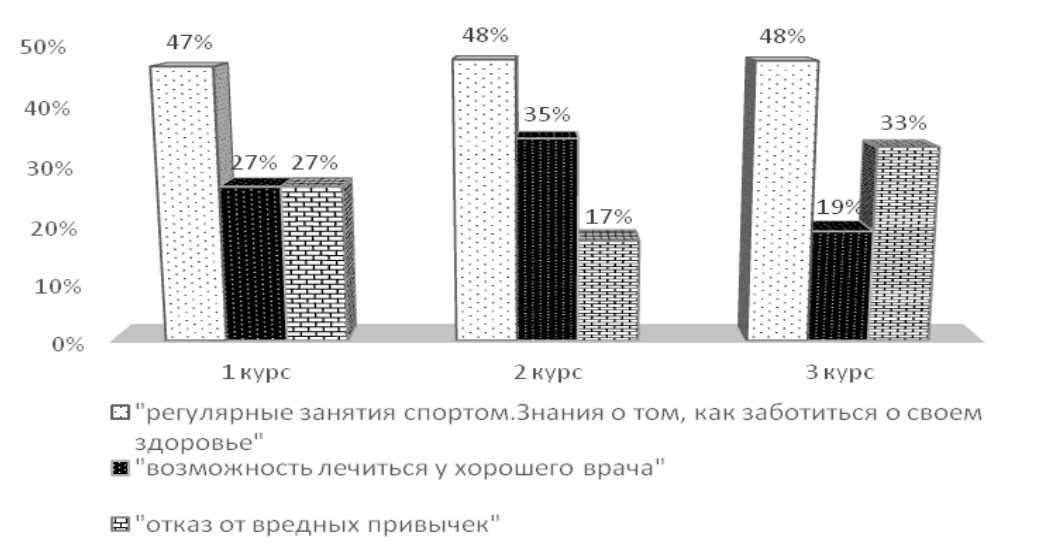

Рис. 8. Наиболее важные условия для сохранения здоровья (\%)

Опираясь на полученные данные, можно сказать, что студенты положительно относятся к вопросу сохранения здоровья, многие из них считают, что необходимо придерживаться принципов здорового образа жизни. Так, для сохранения своего здоровья 47\% первокурсников, $48 \%$ второкурсников и $48 \%$ третьекурсников выбирают регулярные занятия спортом, а также знания о том, как заботиться о своем здоровье. Вторым по популярности является ответ «отказ от вредных привычек», что говорит о готовности студентов изменить свой образ жизни в лучшую сторону.

Об источниках получения информации о культуре и принципах здорового образа жизни, студентам был задан вопрос: «Откуда вы чаще всего слышите о ЗОЖ?» (рис. 7)

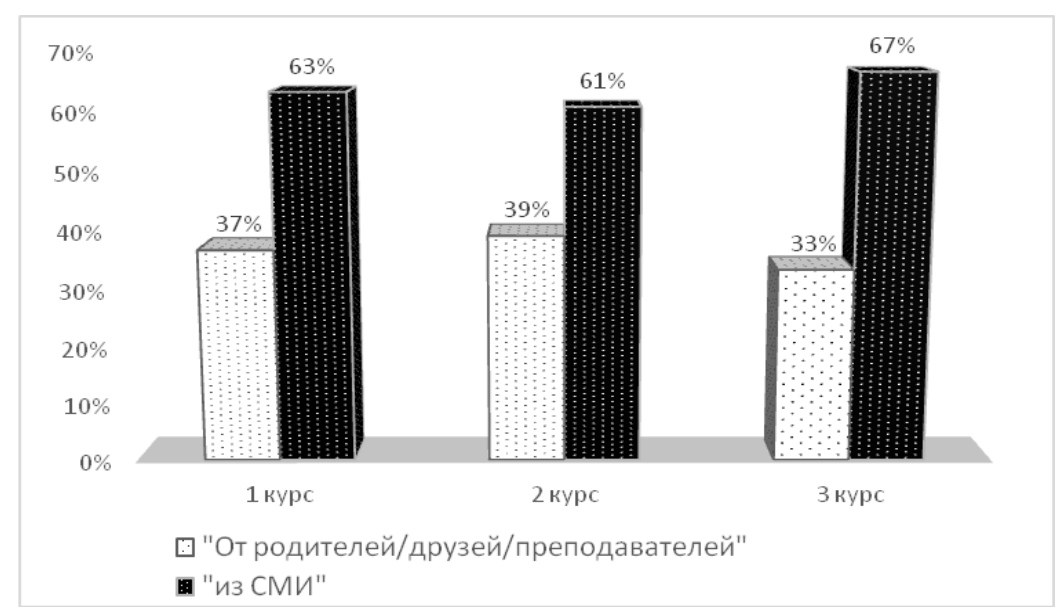

Рис. 7. Поступление информации о ЗОЖ (\%)

Анкетирование показало, что основную информацию о культуре здорового образа жизни, студенты получают из средств массовой информации. Такой источник не всегда является достоверным, поэтому стоит разобраться, каким об- 
разом высшее учебное заведение способно направить студентов на получение знаний о ведении здорового образа жизни. Ведь цель учебного заведения - растить физически и психически здоровых специалистов, формировать у них убеждения в ценности здоровья и учить их ответственно относиться к собственному здоровью.

«Как вы считаете, необходимо ли пропагандировать ЗОЖ среди студентов?» (рис. 8), «Интересно ли вам узнавать о том, как заботиться о своем здоровье» (рис. 9), - с такими вопросами мы обратились к студентам.

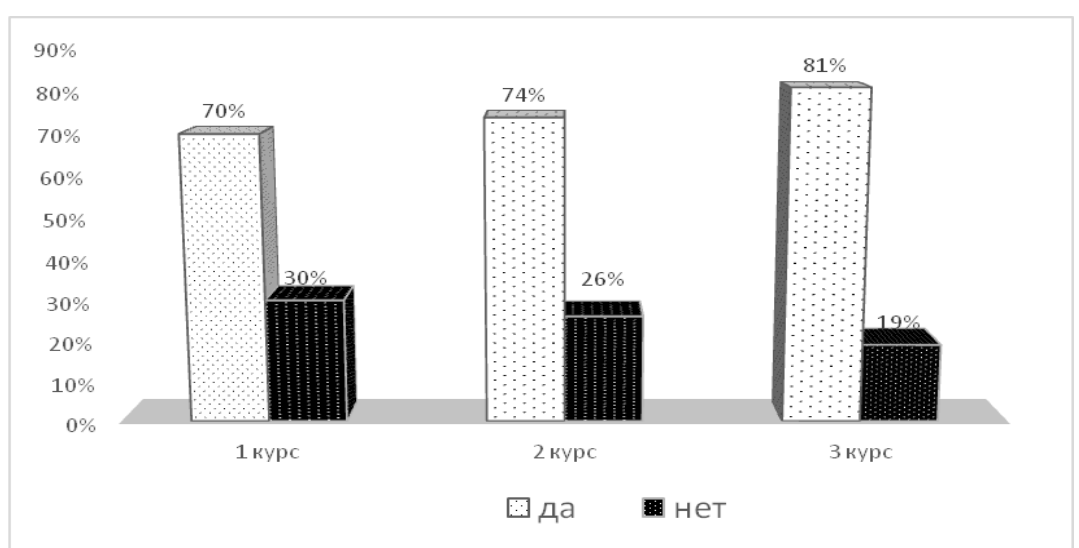

Рис. 8. Необходимо ли пропагандировать ЗОЖ среди студентов (\%)

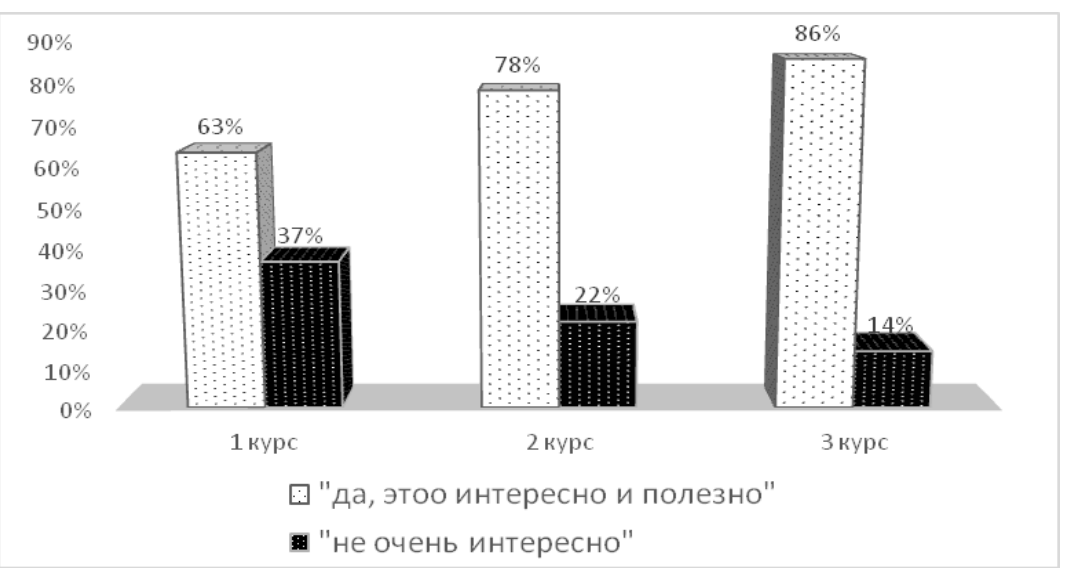

Рис. 9 Интересно ли вам узнавать о том, как заботиться о своем здоровье (\%)

По результатам опроса, можно сделать вывод о том, что большинство студентов заинтересованно в получении информации о принципах здорового образа жизни (63\% первокурсников, 78\% второкурсников и 86\% третьекурсников положительно отреагировали на заданный вопрос). Также многие из них не против пропаганды ЗОЖ в стенах высшего учебного заведения (70\% первокурсников, 74\% второкурсников и $81 \%$ студентов третьего курса одобрили пропаганду ЗОЖ среди студентов). 
На основе проведенного анализа стоит предложить некоторые рекомендации, которые могли бы дать мотивацию и позитивные установки студентам на ведение здорового образа жизни. Мотивацию к занятиям физической культурой можно сформировать или повысить, используя, например, следующие меры:

- проведение разных форм занятий с учетом пожеланий студентов

- привлечение студентов к проведению занятий (например, разминки);

- предоставление студентам возможности посещать занятия в удобное для них время (например, с другими группами) при сохранении обязательного количества часов в неделю;

- организация спартакиад;

- организация бесплатных походов на соревнования и матчи по различным видам спорта;

- показ мотивирующих кинофильмов.

Для укрепления теоретической базы по вопросам сохранения здоровья, следует предложить введение и совершенствование специализированных учебных дисциплин:

- разработка курсов, обучающих студентов различным практикам для улучшения здоровья, психоэмоционального состояния и формирования позитивного мышления;

- разработка образовательных программ, направленных на сохранение и укрепление здоровья молодых людей, формирование активной мотивации заботы о своем здоровье и о здоровье находящихся вокруг людей;

- внедрение в учебный план особой дисциплины валеологии - дисциплины об индивидуальном здоровье человека, о его сохранении и укреплении. Данная дисциплина сформирует у студенчества убеждения в том, что для каждого индивида здоровье является неотъемлемой ценностью, на которую оказывают негативное влияние условия окружающей среды, а также неправильно сформированная физическая и нравственная культура индивида [1].

Также сформировать мотивацию к ведению ЗОЖ возможно не только на занятиях, но и в других повседневных ситуациях студенческой жизни. В каче- 
стве мер, способных мотивировать студентов к правильному питанию и отказу от вредных привычек стоит предложить:

- расположение на территории академии киосков «здорового питания», в которых студентам предлагаются полезные натуральные продукты питания и напитки по доступным ценам;

- расположение в зданиях образовательного учреждения кулеров с горячей и холодной питьевой водой для обеспечения необходимого объема потребляемой жидкости;

- размещение информационных и мотивирующих стендов в зданиях образовательных учреждений и в студенческих общежитиях, трансляция видеороликов, выпуск и распространение тематических университетских газет [1, с. 98].

Таким образом, студенты нуждаются в помощи в направлении пополнения теоретических знаний по вопросам сохранения здоровья и применения этих знаний на практике - организации собственной жизни по принципам ЗОЖ. Основной рекомендацией в этом плане является внедрение курса лекций «Основы ведения ЗОЖ». Цель курса должно стать побуждение студентов к применению знаний по вопросам ЗОЖ на практике. При рассмотрении различных форм и методов воздействия на студентов в целях формирования у них здорового образа жизни в условиях образовательной среды, можно сделать вывод, что наиболее эффективными они будут только в совокупном применении. Для достижения наибольшей эффективности также необходимо внедрять внешние мотивационные факторы. Они могут быть:

- экономические (повышенные или именные стипендии для отличившихся в вопросах здорового образа жизни);

- социальные (например, предоставление талонов на бесплатное здоровое питание в столовых учебного заведения, возможность прохождения медицинских осмотров и получения медицинской помощи на бесплатной льготной основе); 
- а также моральные в виде объявления благодарности и ведения «доски почета» [2, с. 121].

\section{Список литературы}

1. Дёмкина Е.П. Формирование здорового образа жизни студентов: как не упустить главного? / Е.П. Дёмкина // Высшее образование в России. - 2016. -

№5 (201) [Электронный pecypc]. - Режим доступа: https://cyberleninka.ru/article/v/formirovanie-zdorovogo-obraza-zhizni-studentovkak-ne-upustit-glavnogo (дата обращения: 07.03.2019).

2. Наговицын Р.С. Мотивация студентов к занятиям физической культурой в вузе / Р.С. Наговицын // Фундаментальные исследования. - 2011. - №8-2. C. 293-298.

\section{References}

1. Diomkina, E. P. (2016). Formirovanie zdorovogo obraza zhizni studentov: kak ne upustit' glavnogo?. Vysshee obrazovanie v Rossii, 5 (201). Retrieved from https://cyberleninka.ru/article/v/formirovanie-zdorovogo-obraza-zhizni-studentovkak-ne-upustit-glavnogo

2. Nagovitsyn, R. S. (2011). Motivatsiia studentov k zaniatiiam fizicheskoi kul'turoi v vuze. Fundamental'nye issledovaniia, 8, 293-298.

Тиосова Татьяна Николаевна - старший преподаватель кафедры физической подготовки, Владивостокский филиал ГКОУ ВО «Российская таможенная академия», Россия, Владивосток.

Tiosova Tatyana Nikolaevna - senior lecturer of the Department of Physical Training of Vladivostok branch of SOEE of HE "Russian Customs Academy", Russia, Vladivostok. 